\title{
When in Rome
}

\section{Anne Ellen Geller}

St.John's University

In July, Rome is hot. Very hot. In fact, with afternoon temperatures rising to 90 degrees or above, most tourist information suggests that in July the city is just too hot for comfortable sightseeing. By the first of August the city shuts down. Stores close, the streets empty of honking cars and motorbikes, and everyone heads to Malta. But in the last weeks of July, local residents have not yet left the city, and in Rome life is lived, buoyantly, out on the streets.

By day, nuns in deep gray and black habits ride bicycles along the streets by St. Peter's Square. Lush windowboxes, planters, and roof gardens are in full flower. Crowds of tourists line up for the day's Vatican museum tickets, shaded by umbrellas. Mopeds and motorcycles fill the air with smog and noise. The outdoor mercato of Andrea Doria and Testaccio smell of ripe local tomatoes, bulbous fennel, piles of zucchini flowers, fresh sliced prosciutto, and whole fish that are folded into brown paper with lemon slices and parsley. On Sundays, the Porta Portese flea market is dusty and sticky from the watermelon quarters that drip and leave trails of seeds. Throughout the city, cold water flows from more than two hundred nasoni ("big nose") fountains (Donati, 2009). In the early afternoon, apartment windows are shuttered, stores close and residents wait out the mid-day heat.

At dusk, bats fly across the sky above the Forum. The Trastevere neighborhood is strung with lights and filled with processions for Festa de' Noantri, in honor of the Madonna del Carmine. On street after street throughout the city, the dining rooms of trattorias are empty, but candlelit sidewalk tables covered in patterned plastic tablecloths or white linens are crowded, lively, smoky and filled with voices and laughter. Everyone drinks vino de casa rosso or bianco and then strolls, licking gelato as it melts down the sides of cones.

In the summers of 2007 and 2008 St. John's faculty arrived in the city in the midst of all of this and spent two weeks working together at the university's campus in the Prati section of Rome as participants in a program that was half faculty writing retreat and half writing across the curriculum faculty development workshop. When St. John's first conceived of the Summer Faculty Writing Institute, senior administrators hoped a summer writing retreat at the universi- 
ty's Rome campus might be enticing enough to convince faculty to rethink how they used writing in their teaching. The administrators also imagined faculty who traveled to the campus could become ambassadors, who would, based on their own experiences in Italy, actively recruit students for study abroad, helping to raise their numbers. Further, they hoped travelling to Rome as students might lead faculty to want to return to the Rome campus to teach.

In November 2008, six faculty who took part in the Writing Institute and I presented at the Quinnipiac University Conference on Thinking and Writing. After our presentation an audience member raised his hand and said: "Don't you feel as if your university is pushing Catholicism by funding faculty trips to Rome? I think this is just another step toward losing your academic freedom." While the faculty and I all thought his concerns exaggerated, he did ask a better question than he may have realized: Just what was behind the idea to hold this faculty development program in Rome?

In some ways, the answer is obvious. By stated mission, St. John's University is "Catholic, Vincentian, and metropolitan." It's not as if the faculty who spoke on the panel at Quinnipiac are unaware of what it means to research and teach at a Catholic institution in an era when the current Pope has called for American Catholic institutions "to emphasize their Catholicism" (Banerjee, 2008). St. John's is - and will always be - connected to the Vincentians, to the Vatican and to the Pope. Our "campus" in Rome is actually a Vincentian residence in which some floors have been renovated to include classrooms and dormitory space. The building is still partly inhabited by priests.

The university's mission has recently been revised to reach beyond New York City's five boroughs and now reads: "St. John's is a metropolitan university. We benefit from New York City's cultural diversity, its intellectual and artistic resources, and the unique professional educational opportunities offered by New York, Rome and other cities throughout the world where our students study and serve" (St. John's University Mission Statement). The university draws attention in print and electronic materials to its interconnected campuses in New York - Queens, Staten Island, Manhattan, and Oakdale, — and one international campus in Rome, Italy. Indeed, when participants in the Summer Faculty Writing Institute arrived in Italy they each received laminated St. John's identification cards (just as any study abroad student would) imprinted with "Rome Campus" and featuring the same picture as the one on their Queens or Staten Island, New York campus ID. The campuses are this 
connected, down to level of the computer network and building access.

It's true that the focus of the St. John's University Summer Faculty Writing Institute - writing and the teaching of writing - may not be academically connected to the locale, the city of Rome, in the ways some study abroad programs connect disciplinary content and geographical location. And yet to see St. John's University's ulterior motives for supporting this program as based only in Catholicism - or worse, conversion — is to miss that where an institution sends its faculty and why it decides to support faculty study abroad to certain locales - or certain cities - may make more subtle aspects of institutional mission, goals and values visible to faculty in important, tangible ways that can later inform faculty and students' teaching and learning. Also, as other research studies — and our experiences at St. John's — reveal, creating a scholarly, reflective space for faculty to build a learning community far from their daily lives on a campus in the United States, whether it's a research community, or, in this case, a writing community, may be one of the best investments in faculty development and global education an institution can make.

\section{Why Rome?}

It is easy to understand why, even beyond the power and reach of institutional mission, St. John's has invested in Rome as one of its premiere study abroad sites. Rome is a city one can enter and comfortably inhabit quite quickly, even as a newcomer, which makes it ideal for study abroad learning. It is a safe city (despite hype that pickpockets are everywhere), has a reliable and navigatable public transportation system of underground trains and above ground buses, and, even with the smog and the crazy traffic, it is walkable.

Those in Rome desperate for fast food will find McDonald's (not surprisingly next to the largest tourist attractions), but the more traditional tempos of eating in the city mean students and faculty find few take-out cups of coffee and become accustomed to standing at bars to sip morning espresso alongside Romans. Restaurant dinners are slow and open-ended, with multiple courses served separately, so there is more mealtime for conversation, something unfamiliar, but welcome, to many Americans.

Rome is internationally diverse city. Visitors with a variety of first languages who try to communicate while consulting dictionaries are not only encouraged but often supported in their attempts to ask questions in Italian. But even though language may not be a barrier to interaction in the city, 
visitors from the United States, especially those who have never travelled internationally or not done so very often, can still experience some palpable culture shock. For example, there are no twenty-four hour chain drug stores, no informal, impersonal CVSs or Walgreens, within Rome. Thus, St. John's faculty member who forgot to pack deodorant had to order his purchase (in Italian) from a white-coated employee who slid open the after-hours front window of a pharmacy. Others had to adjust to asking for and not getting ice in their cold drinks, pushing open doors to find mixed gender bathrooms (even at the St. John's campus) or not having cell phones always at hand. Living across an ocean from what was familiar and being confronted with simple differences in culture led to loneliness, embarrassment, discomfort and confusion - as well as self-reflection, curiosity and learning. For the faculty members who had never studied abroad as students, these were particularly eye-opening moments that left them experiencing exactly what students studying abroad do.

Throughout Rome, imposing cultural institutions are juxtaposed with the rhythms of everyday street life. Commuters with briefcases and children with schoolbags take the same morning trains as tourists streaming to St. Peter's. Art by Michelangelo and Caravaggio is accessible in neighborhood churches. Rome's history is so much older and so much deeper than that of American cities, or even many other European cities, there is a palpable sense that no matter where one stands one is travelling through time.

The first day I ever spent in Rome, a colleague and I walked through the Jewish Ghetto on our own, marveling at the way centuries of buildings had literally been built around unmovable ruins from more than two thousand years ago. Archaeologists, I often say, find full-time work in Rome, where careful excavations are taking place under tents and yet in full view. On a walking tour, I listened to a guide speak of how Rome has always been built on existing structures, and he pointed out the many churches with pagan temples below and the scavi below the Vatican. There is a world below every building, the guide suggested, a world we still may not even know about and may never know the truth about, like whether St. Peter's bones were really found under St. Peter's Basilica. In Rome, there are likely still "patches of the subterranean city, or rather cities" (Weaver, 1985) we have not yet even learned about.

In 2008, Maura Flannery, a faculty participant, was writing about the 
four different layers of temples and churches at San Clemente. With Maura I began thinking aloud about one of the goals of the institute: helping faculty excavate the layers of their teaching philosophies and pedagogies to build new philosophies and pedagogies in place of and around the old. As director of the University's Center for Teaching and Learning, Maura could see the connection I saw between the city and our work with faculty.

Earlier in that year's institute, on a day when twelve of us were eating lunch together, the senior faculty at the table began to tell stories of a St. John's University the younger faculty did not know. They described watching as the institution changed in unexpected ways and built upon itself, and they explained how the institution had retained some of what it had always been, through different deans, different strategic plans and different times. In a city where new was built upon old, and the ancient sat comfortably (or uncomfortably) alongside the contemporary, faculty participants had space and time to reflect on the institutional, scholarly and pedagogical pasts their presents are built upon and their futures as scholars and teachers could grow from. Travelling around Rome's literal, physical layers outside our classroom hours provided a metaphor for the more cerebral and emotional exploration of academic life that the formal and informal work of the Summer Faculty Writing institute encourages.

\section{The Summer Faculty Writing Institute - A Writing Retreat and Writing Across the Curriculum Workshop}

Although I direct the Summer Faculty Writing Institute, and I was invited to take part in the first one six weeks before my faculty position officially began, the plans for the retreat predated my arrival at St. John's University. What I learned - after two Summer Faculty Writing Institutes in Rome - was that the idea actually originated (in a "purely conceptual way") in the mind of one senior faculty administrator, James Benson, who emailed the provost and my senior colleague, the Director of the Institute for Writing Studies, saying: "I am convinced that if faculty members spent a summer writing, writing, writing, ... they would be more effective at encouraging and teaching students to write in their disciplines" (J. Benson, personal communication, October 30, 2008). He suggested creating an opportunity for "writing, writing, writing" and "feedback, feedback, feedback" from "peers and writing counselors" (meaning the faculty affiliated with the Institute for 
Writing Studies). He also suggested the environment should be a "writing colony/workshop type of environment away from campus, possibly abroad," a suggestion heartily supported by the university's Provost and President. While many institutions - in the US and abroad (Moore, 2003, Grant and Knowles, 2000) - have begun to more regularly offer faculty writing retreats (Farr, Cavallaro, Civil \& Cochrane, 2009) or boot camps ${ }^{1}$ to encourage and support faculty writing, I know of no other faculty writing programs hosted by US institutions at their international campuses.

In suggesting a "writing colony/workshop type of environment," James Benson, now Vice Provost and Dean of University Information Resources \& Libraries at St. John's, was invoking a long, romantic tradition of the seclusion considered necessary for solitary authorship. As Jane Piirto (2005) writes: “The appeal of writers' retreats and colonies is that of peace and quiet away from the melee, so that the creative spirit can descend. At Yaddo, a writers' retreat, lunch is delivered in baskets to the writers hard at work in their cottages. Advertisements for such retreats promise remoteness, stillness and solitude" (p. 9). Fiction writers and poets who flock to Yaddo, the Vermont Work Center, or Bread Loaf, all well established American writing retreats, find this solitude, but they also find communal dinners, evening readings, opportunities to network and collaborate with other writers, and even pick up softball games.

Research on the processes of successful faculty writers suggests access to a community of colleagues is as important as solitude, so those noisy dinners and softball games may be important too. Sarah Moore (2003) notes those "writing as part of a community of writers are more likely to learn faster about the conventions and challenges of writing, to support each other at times of blockage and to demystify the process of writing by sharing each others' successes and failures", and she points out how such an "approach challenges many of the cultural and competitive conventions of academic life” (p. 334). Or, as Barbara Grant and Sally Knowles (2000) write, "while the act of writing is most often performed in private (hence perhaps the unrealistic ideas about how others write), it may usefully be rethought as a social act," through "the lived experience of being a member of a community of writers" (p. 10). For:

In this different, social, scene of writing, the production of text is experienced as a messy process of engagement with the word and the world, and is integrally tied up with revision and response. The risk of ultimate exposure, which may prevent us from ever starting to write, is pre-empted 
by multiple exposures to others in the community along the way. (p. 11)

I have been struck by the fact that the earliest writing across the curriculum efforts at American institutions in the 1970s and 1980s often combined support for and encouragement of faculty writing with collective inquiry around the teaching of writing. ${ }^{2}$ These efforts are now more often separated. Faculty attend the type of writing retreat or bootcamp described above to work on their own writing among their scholar colleagues, and they attend writing or communication across the curriculum workshops or institutes to consider their teaching of writing among their teacher colleagues ${ }^{3}$. Thus the two types of learning - learning to be a more successful academic writer oneself and learning to be a more successful teacher of writing - are separated. And faculty find the roles they inhabit - scholar and teacher - split, even as they are told these roles are and should be intertwined. We knew we wanted faculty in the Summer Faculty Writing Institute to feel we were encouraging them to bring these roles together.

For both Summer Faculty Writing Institutes, participants were flown to Rome, provided with private accommodations in a residence, breakfast and lunch during the week of the institute (or, as was the case in the second summer, a per diem for these meals) and a group welcome dinner. As an added incentive, faculty could invite family members to join them for the second week of the trip. While the university does not pay for airfare for these family members, accommodations are covered for family members for the second week. The number of these guests varied by faculty person; while some faculty invited only a spouse (one faculty person used it as a ten-year anniversary trip with her husband), others had children join come to Rome the second week. When one faculty person's family could not attend, that person asked to bring lifelong friends - a colleague who retired from his department and the colleague's wife.

In 2007, pre-trip preparation was informal, but in 2008 there were two spring meetings for participants. Prior to leaving for Rome, faculty were asked to gather a variety of materials (sample assignments from their own courses, articles about teaching writing from journals in their disciplines, portions of the writing projects they would be sharing with one another). The purpose was to get faculty thinking about their own writing, how they teach writing, and their colleagues' writing and teaching. And as a way of encouraging fac- 
ulty to experiment further with and utilize the course management software site before arriving in Rome, they were asked to post and respond to a variety of materials which we referred back to often during our Rome Institute. For example: One faculty member who had posted an article about teaching writing in her discipline realized in the middle of the week's work in Rome that she could take on pedagogical research in her own class similar to that described in the article. Another faculty member referred his colleagues to uploaded writing assignments and rubrics he was already successfully using.

During the first five days in Rome faculty worked in small and large groups in morning and afternoon workshops, and, in between, continued to talk over lunch (See Appendix 1: The Workshop Schedule). In addition to these workshops, faculty were divided into "writing groups," and they met during meals and evening hours to further discuss their own writing. Also, every morning before the beginning of workshops, faculty had several hours to write.

Faculty also contributed their own scholarly and creative interests to the group. For example, toward the end of the 2008 Summer Faculty Writing Institute, Lee Ann Brown, a faculty participant who is a poet, led the group in writing a collaborative renga, a modern version of a traditional Japanese linked poem. We each wrote a haiku from images reconstructed from our lunch break. And then we each wrote two additional lines about writing or the week's learning. That rhythmic linking of all our experiences inside the classroom at the Rome campus and outside the campus in Rome itself, stays with me. (See Appendix 2: Excerpt of Renga Roma)

Many faculty who attended had known one another for years, but because faculty were together for a week, new relationships were also built. Like students who meet and come to know one another while studying abroad when they may not have been friends on campus, this was made possible by being more than 4,000 miles from the context in which faculty usually interacted — or didn't - with one another. For the second week of the Institute, two days of touring for the entire group of faculty and families are conducted by Otto Garcia, a New York based Monsignor who in the past has served on the St. John's University Board of Directors. The energetic and enthusiastic Monsignor, whose love of Rome dates back to his own days as a student at the Gregorian University, leads both walking and bus tours of the city, and we are fortunate to have this institutional connection who can introduce us to the city on the ground.

One day's walking tour begins with an exploration of St. Peter's Basilica. 
A tour guide like Monsignor Garcia can explain the significance of each chapel, talk the group slowly around the Bernini alter with its Barbarini bees, and tell a bit of history about each interred Pope. Once that walking tour leaves the Vatican, an independent country all its own guarded by the Pontifical Swiss Guard, Monsignor Garcia moves us through the sidestreets of the Via della Conciliazione to the Tiber, to lunch on his favorite calzones near the Pantheon, and to drink an after lunch coffee granita at Tazza D'Oro before the Church of Santa Maria with its Bernini elephant obelisk outside. Then, through the Jewish Ghetto, to the Piazza del Campidoglio, down the Cordonata steps, and on to the Coliseum and the Forum. Everyone is tired, dusty, hot, and excited by how much more they've learned about the city.

The second day is a bus tour, which allows us to see more of the important sites spread out within the walls of Rome than we would be able to walk to - like the Scala Sancta (the Holy Stairs), the Basilica of St. John Lateran, and the Basilica of Saint Mary Major. But touring by bus also allows us to take fifty people beyond the old walls of the city to St. Paul's Beyond the Walls, the catacombs of the Appian Way, and the pyramid of Cestius and the Protestant Cemetery (with graves of Keats, Shelley, Gramsci and Corso), both in Testaccio. This second day includes a lunch at which talk echoes with the work of the previous week. Certainly, visiting every one of the four major basilicas with a priest brought faculty close to the richness of Catholicism in Rome, as did watching a tourist couple stop him at the Catacombs of St. Cecilia to ask him to bless their wedding rings. But, for academic faculty, not all of them Catholic, sightseeing with Monsignor Garcia is not just about Catholicism. His tours are expert teaching - lecture, discussion, experiential learning, question and answer. He draws on comparative religion, art history, archaeology, sociology, and even literature, embodying for our group what is possible through study abroad: embracing a place and becoming both curious and knowledgeable about local history and culture while immersed within it.

\section{The Value of Faculty Study Abroad}

No one conceived of the Summer Faculty Writing Institute as faculty study abroad, but the more I learn about global study for faculty, the more I think of the program as exactly that: a two week short term study abroad experience which positions the faculty as learners. And colleges and universi- 
ties have begun to see the value of investing in faculty study abroad, expensive as it may be. A 2008 Chronicle of Higher Education article reports Madeline F. Green, former vice president of international initiatives for the American Council on Education, as saying "faculty members can present a major barrier to colleges' international efforts" for "they may have spent little time out of the country, see their discipline in strictly American terms, or consider study abroad as nothing more than a diversion" (Fischer, 2008). Green is quoted: "I tell presidents if they have any money at all for internationalization, faculty development is the place to put it."' The article highlights a program at Rollins College through which the president "has pledged to send every faculty and staff member with teaching duties abroad once every three years" (Fischer, 2008). Similar, smaller scale faculty travel programs reported in the same article exist at Rhodes, Grinnell, Maricopa County Community College District, and the University of Richmond.

The Summer Faculty Writing Institute in Rome has taught me that there are questions all of our institutions should be considering: What are the study abroad possibilities at an institution and how can those possibilities best be leveraged for faculty development programs? For example, my previous institution has a popular and longstanding May term session in Luxembourg. How could that same session for students engage faculty in new ways? And how could involving faculty in a study abroad program so connected to the institution help faculty build unexpected, and maybe even currently unarticulated, connections to institutional mission? Many faculty study abroad programs bring faculty to specific locales for research or disciplinary learning connected to those places - for example, Texas A\&M's program takes faculty to study "the culture, history, government, business and language of Mexico" so they "incorporate applicable global experiences into their teaching and research programs" (Dooley and Rouse, 2009, p. 163). While the program described here may not promote that same type of individual global, scholarly engagement with Rome, it models the possibilities for creating faculty learning (and thus changes in faculty teaching) in places that are institutionally important, and thus may become individually important to faculty.

The benefits of faculty study abroad for institutions, but also for faculty and students, seem positive (Dooley and Rouse, 2009). Because of faculty study abroad, the University of Richmond reports growth in the number of 
agreements for faculty and student exchanges — " 60 such arrangements with foreign institutions” (Fischer, 2008). Student study abroad participation is up at Rollins, perhaps because more faculty are "evangelists for overseas study," and Rhodes notes new courses developed (Fischer, 2008). In more in-depth studies of the impact of faculty study abroad, researchers note:

The experience of being immersed in a foreign culture, even for a short time, causes a transformation in many individuals that cannot be easily achieved by other means. Faculty participants $[. .$.$] consistently$ commented that no matter how much previous study they had done of the cultures they visited, nothing could compare with actually being there. Many referred to the sensory experience, to the sights and smells and sounds that made the places and the people real to them. (Sandgren, Ellig, Hovde, Krejci \& Rice, 1999, p. 54)

Much of what stays with me, and with others from the program, is sensory: images of Rome's ruins and churches, the feel of the city's heat, the smell of the markets, and the sound of Roman's relentlessly quick Italian. I also think many of the participants in the Summer Faculty Writing Institute now have a different understanding of and relationship to the symbols, sites and history of Catholicism. And I'm not sure why we should be suspicious of this learning. When I see the participants from these learning communities formed abroad interact with one another on campus, I know they now have relationships to one another and the institution - and to one another's writing and teaching — that I don't believe could have been formed on campus.

\section{The Return to Campus}

St. John's faculty agreed that being in Rome was key to the Institute's success. Sustained reflection and dialogue seemed more feasible so far away from responsibilities on campus and at home, as did the possibility of thinking of oneself as a writer. One senior faculty participant has said over and over again that the Institute was the first time in all her years at St. John's she felt her writing was noticed, encouraged and supported. A number of faculty, successful as publishing scholars, were outspoken in Rome about their writing apprehensions - one felt more like a reader who tries to write, others were anxious about argumentation and academic prose. Some found 
writing a chore but believed other colleagues write effortlessly. One felt blocked for fear of spelling errors. These are issues we might tell our students not to worry about, yet they are issues that we, as faculty writers, can seldom disclose to our peers and often find extremely stressful.

Other faculty offered these quotes about their teaching since participating in the Institute:

The Rome experience... made me view many aspects of my teaching in a different light, especially in regard to the information gained by the interaction with my colleagues from other departments.

I felt that for the first time the university faculty were getting to speak to each other outside of the context their own departments' narrow writing "missions" and think more broadly about our different expectations for students. These experiences have been crucial moments in my professional development and pedagogical thinking.

The 2008 Faculty Summer Writing Institute was formative in my efforts to incorporate writing assignments in my large introductory psychology core course as well as my use of Blackboard to facilitate communication and provide greater opportunities for student engagement. As a result of my experience at the Institute, I have for the first time incorporated a writing assignment in Psychology 1000c in the form of a "writing to learn" assignment in which students post journal entries in a filing cabinet on the Blackboard page based on their reflections on concepts discussed in the textbook.

In terms of the teaching and learning we'd hoped to accomplish in relation to writing across the curriculum, what we've found is that when faculty are with unfamiliar colleagues at an international campus, they are more willing to experiment. For example, although all the faculty had university laptops, many had never used them for teaching and learning before utilizing them with one another as a part of the Summer Faculty Writing Institute. Since Rome, these faculty are using online course management tools, which leads to asking students to write more, often to one another and in a variety of different genres. Faculty adoption of technology - a priority for a laptop campus - was only one of the unforeseen effects of faculty working 
with one another. Asking faculty bring their laptops along for real-time use (both in their work with one another and as a way to communicate with their families at home) was significant to this effect.

But there are additional on campus effects of the two Summer Faculty Writing Institutes. Five faculty members from psychology are now facilitating departmental conversations about writing with their colleagues. Two faculty, from two different years of the program, are now involved with an on-campus Faculty Writing Initiative that has already sponsored an oncampus writing retreat and encouraged the formation of on-campus faculty writing groups. A participant from the sciences and I are faculty co-chairs of a re-envisioning of student research day as student research week - a longer, more inclusive celebration of student scholarship, research and creative endeavors across the disciplines. Even disciplinary publications grew from interaction with the city and its landmarks (for example, Maura Flannery's "Writing Across Rome" in The American Biology Teacher).

Although it is unclear if faculty members have had a direct impact on the number of St. John's students studying abroad, there has been a tremendous rise in study abroad enrollments. In fact, by late October 2009, registration for the university's spring 2010 programs in both Rome and Paris had already closed. Further, just as the original supporters of the program had hoped, seven of the thirty participants in the Summer Faculty Writing Institute have now taught abroad or are planning to teach abroad. Four have returned or are returning to teach courses at the Rome campus, offering a much wider variety of curricular choices than have been available there before and some of these curricular choices are place dependent. For example, in summer 2010 a sociologist who took part in the Summer Faculty Writing Institute will teach a graduate criminology course entitled "Crime and Justice in Italy," while two other past participants have taught in the university's new Freshman Passport Program in Rome. Through this program, students in core general education courses at St. John's like "English Composition" or "Discover New York" take a pre-semester or post-semester two week trip to the Rome campus that includes writing about the city and taking part in service opportunities within the city ${ }^{4}$. Introductory psychology will be offered at the university's campus in Paris this summer, taught by another Rome faculty participant.

These faculty say they wouldn't have thought of teaching abroad if they 
hadn't first travelled to Rome with their colleagues to write and think about writing. They learned they could travel abroad, be ready to teach and learn once they arrived, and combine classroom study with out-of-class exploration. I believe many of us will continue to find ways to connect our disciplinary interests with Rome simply because we were there, in the city, on the ground. For example, I imagine the sociologist might not have thought to propose a class on crime and justice in Italy if we had not walked past Rome's austere court buildings every morning on the way from our residence to the campus and again on the way home at the end of the day. This new course truly extends "metropolitan" and "cities of the world" of the university's mission into the curriculum, and it came about, along with many other changes in faculty teaching and learning, because we made the decision to extend faculty development from our New York campuses to Rome.

Because of the economy, we have postponed the Summer Faculty Writing Institute for two summers, but we hope to reinstate it for the summer of 2011 and hold it biannually after that. In the future, I would like to find a way that St. John's faculty can interact with faculty from Rome, who live and write and teach in the city of Rome as our faculty live and write and teach in the city of New York. When asked to reflect on the weeks in Rome and suggest changes, almost all St. John's faculty craved more retreat time for their own writing and more time to work with one another's writing. But almost no one wanted to give up time thinking about teaching with their colleagues. As one participant said aloud, who would trade this satisfying time talking with those we never get to know to do the solitary work we'll always have to do? So faculty suggested adding a few more days of writing retreat to the week, or starting to work with one another's writing before the weeks away and after returning. Our disciplines are very different, another participant said, but what we all have in common is writing and teaching. And, I would say, Rome. Sometimes we think of moving this program to another of the popular St. John's student study abroad sites. ${ }^{5}$ Paris, perhaps. But much as we dream of traveling to another city, all of us at St. John's, it seems, will always be connected to Rome. And utilizing that connection - how Rome can introduce faculty to one another, to writing, to teaching writing, and to institutional mission - is what becomes most valuable. ${ }^{6}$ 


\section{References}

Banerjee, N. (2009, April 18). At University Visited by Pope, Students Find a Catholicism That's 'Not in Your Face'. The New York Times. Retrieved from http://www.nytimes.com

Donati, J. (2009, October 14). In Rome, an Easier Way to Quench Thirst. Transit Blog: The New York Times. Retrieved from http://www.nytimes.com

Dooley, K. E., \& Rouse, L. A. (2009). Longitudinal Impacts of a Faculty Abroad Program: 1994-2007. Proceedings of the 25th Annual Meeting, 2009 Association of International Agricultural and Extension Education (AIAEE). Retrieved from http://www.aiaee.org/2009/Papers/160.pdf

Farr, C. K., Cavallaro, J., Civil, G, \& Cochrane, S. (2009). Taming the Publishing Beast: The College of St. Catherine Scholars' Retreat. Change Magazine. Retrieved from http://www.changemag.org/MayJune\%202009/full-publishing-beast.html.

Fischer, K. (2008, October 31) Professors Get Their Own Study-Abroad Programs. Chronicle of Higher Education. Retrieved from http://www. chronicle.com

Flannery, M. (2009). Writing Across Rome. The American Biology Teacher. $71(1), 52-55$.

Grant, B., \& Knowles, S. (2000). Flights of imagination: Academic women be(com)ing writers. International Journal of Academic Development 5(1), 6-19.

Mission Statement of St. John's University, New York. (2008) Retrieved from http://www.stjohns.edu/about/general/mission

Moore, S. (2003). Writers' Retreats for Academics: Exploring and Increasing the Motivation to Write. Journal of Higher and Further Education 27(3), $333-342$.

Piirto, J. (2005). The Creative Process in Poets. In J. C. Kaufman and J. Baer (eds), Creativity Across Domains: Faces of the Muse (pp. 1-21). Mahwah, NJ: Lawrence Erlbaum Associates, Inc.

Sandgren, D., Ellig, N., Hovde, P., Krejci, M, \& Rice, M. (1999). How International Experience Affects Teaching: Understanding the Impact of Faculty Study Abroad. Journal of Studies in International Education, 3(33), 33-56.

Weaver, W. (1985, October 6). The City Beneath Rome. The New York Times. Retrieved from http://www.nytimes.com 


\section{End not es}

1 See Temple University: http://www.temple.edu/writingctr/facultyservices/facultywritingretreat.html or Wright State University: http://www.wrightstatewac.com/bootcamp.html).

2 For examples, see $A$ History of Writing Across the Curriculum: Composing a Community, Eds. Susan H. McLeod and Margot Iris Sovern.

3 For examples, see University of California Davis, University Writing Program Faculty Writing Workshop: http://writing.ucdavis.edu/programinformation/the-workshop-program/about or North Carolina State Campus Writing and Speaking Program, Faculty Workshops: http://www2. chass.ncsu.edu/CWSP/faculty_workshops.html

4 Description of the St. John's Freshman Passport Program: http://www. stjohns.edu/academics/international/globalstudies/programs/freshman_ passport

5 St. John's University has a popular "Discover the World: Europe” program. Students study for two five week sessions in Rome and Paris, then choose a third five week session in Dublin or Salamanca: http://www.stjohns.edu/ academics/international/globalstudies/programs/semester/europe

6 For helpful feedback on earlier drafts of this essay, many thanks to Betsy Brewer, Michael Monahan, Derek Owens, Michele Eodice and Gino Dilorio, Thanks to St. John's University for my experiences in the Summer Faculty Writing Institute in Rome. 